\title{
Erratum to: What Change in American Shoulder and Elbow Surgeons Score Represents a Clinically Important Change After Shoulder Arthroplasty?
}

\author{
Brian C. Werner MD, Brenda Chang MS, MPH, Joseph T. Nguyen MPH, \\ David M. Dines MD, Lawrence V. Gulotta MD
}

Published online: 13 October 2016

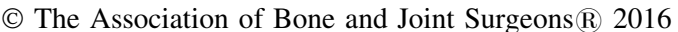

\section{Erratum to: Clin Orthop Relat Res DOI 10.1007/s11999-016-4968-z}

One of the authors of the study, "What Change in American Shoulder and Elbow Surgeons Score Represents a Clinically Important Change After Shoulder Arthroplasty?" listed the incorrect dollar amount range in his conflict of interest statement.
The correct conflict of interest statement for David M. Dines MD should be: "One of the authors certifies that he, (DMD) or a member of his immediate family, has or may receive payments or benefits, during the study period, an amount of USD 100,001-USD 1,000,000 from Biomet, Inc (Warsaw, IN, USA)."

The authors apologize for the error.

The online version of the original article can be found under doi:10. 1007/s11999-016-4968-z.

B. C. Werner $(\bowtie)$

Department of Orthopaedic Surgery, University of Virginia, 400

Ray C. Hunt Drive, Suite 330, Charlottesville, VA 22903, USA

e-mail: bcw4x@virginia.edu

B. Chang, J. T. Nguyen, D. M. Dines, L. V. Gulotta

Department of Sports Medicine and Shoulder Surgery, Hospital

for Special Surgery, New York, NY, USA 